\title{
Geografia eleitoral e manutenção do poder: a importância das bases eleitorais para a reeleição do executivo estadual
}

\author{
Jayane Maia
}

\section{Resumo}

No Brasil a compreensão da dinâmica da reeleição em termos geográficos é importante para o entendimento das estratégias políticas usadas pelos candidatos e do comportamento do eleitorado. O objetivo do estudo é verificar se há estabilidade geográfica da votação dos distritos informais quando ocorre a reeleição do grupo que está no poder e em qual cenário essa estabilidade é mais propensa, considerando quando é o candidato ou o partido que tentam se reeleger ou quando o partido tenta se manter no poder se inserindo em uma coligação partidária. O período de análise dos cenários será pares de eleições: 1998 e 2002, 2002 e 2006 e 2006 e 2010. Os dados amostrais indicam que a possibilidade de sucesso de reeleição e de manutenção da votação nos distritos informais é maior quando o partido lança o candidato que foi vitorioso na eleição anterior, o que reitera a preponderância do voto personalista no Brasil.

Palavras-chave: reeleição; geografia eleitoral; candidato; partido político; coligação partidária.

\begin{abstract}
In Brazil to understand the dynamics of re-election in geographical terms is important for understanding the political strategies used by candidates and the electorate's behavior component. The objective of the study is to check for geographic stability of informal voting districts reelection when the group is in power and that stability which scenario is more likely, considering when the candidate or the party trying to get reelected occurs or when the party is tries to trying to remain in power by inserting in a party coalition. The period of scenarios' analysis are pairs of elections: 1998 and 2002, 2002 and 2006 and 2006 and 2010. The sample data indicate that the possibility of successful re-election and maintenance of informal voting in districts is higher when the party launches the candidate who was victorious in the previous election, which reiterates the preponderance of personalistic voting in Brazil.
\end{abstract}

Keywords: reelection; electoral geography; candidate; political party; party coalition.

Artigo recebido em 12 de junho de 20I4. Aprovado em 2 de novembro de 2014.

\section{Sobre a autora}

Bacharela em Ciência Política pela Universidade de Brasília (UnB) e mestranda em Sociologia também pela UnB. E-mail: jayane.maia08@gmail.com 


\section{Introdução}

A competição política é um aspecto que caracteriza a democracia representativa. No cenário em que candidatos e partidos disputam as preferências dos eleitores, a ciência política ligada à geografia eleitoral procura desvendar o porquê de alguns deles receberem maior apoio político em determinados lugares do que em outros (Soares e Terron, 2008, p. 275). Entretanto, antes de procurar justificativas para a distribuição espacial dos votos para determinado candidato ou político, se faz necessário identificar qual é essa distribuição e qual é a sua dinâmica de uma eleição para outra.

A literatura sobre geografia do voto no Brasil ainda é escassa e requer ampliação, de modo que poucos estudos existentes sobre o tema se debruçam sobre a centralidade da dimensão geográfica nas reeleições. Verificar se existe "coesão regional das bases geoeleitorais" (Soares e Terron, 2008, p. 270) de um candidato reeleito no período entre duas eleições é um passo importante para explicar a sua vitória nas urnas.

A visualização cartográfica da distribuição espacial da votação recebida por um candidato ou partido é significativa na medida em que se podem identificar as regiões onde a votação foi expressiva para a vitória daquele que alcançou algum cargo público. Essas regiões comumente são chamadas de bases eleitorais e a identificação delas pode ser de grande relevância para aqueles que almejam se reeleger ou ter apoio político para a candidatura a outro cargo. A partir disso, é possível, posteriormente, realizar estudos mais profundos e levantar hipóteses sobre o que fez com que a votação dessas localidades permanecesse coesa (estável) de uma eleição para outra.

Nesse sentido, o objetivo principal do estudo aqui realizado é verificar se há estabilidade na distribuição dos votos para os governadores reeleitos entre os seguintes pares de eleições: 1998 e 2002, 2002 e 2006 e 2006 e 2010. Serão realizados estudos de caso em alguns dos estados brasileiros, considerando o cenário observado. Procura-se examinar se há regularidade na votação dos distritos informais na reeleição dos governadores e em qual cenário essa estabilidade é mais propensa de ocorrer, considerando quando é o candidato ou o partido que tentam se reeleger e ainda quando o partido tenta se manter no poder, não encabeçando uma eleição, mas se inserindo em uma coligação partidária. 
O estudo se justifica por preencher, ainda que minimamente, a lacuna existente na análise dos determinantes para a reeleição do executivo estadual. As análises referentes à geografia do voto comumente analisam a interferência de fatores espaciais sobre o comportamento dos congressistas do poder legislativo (Carvalho, 2003; Neves, 2010) e marginalizam pesquisas que tenham como unidade de análise os governadores estaduais.

\section{I.As bases eleitorais na reeleição de candidato, partido e "coligação"}

Frequentemente o candidato é citado como o ator principal no processo eleitoral brasileiro e isso faz com que a sua vitória seja muitas vezes associada ao que a literatura chama de modelo distributivista (Carvalho, 2003), baseado nas negociações em torno da alocação de benefícios políticos, financeiros, materiais, etc. Nele, o candidato, visando a sua eleição ou permanência no poder, utiliza como estratégia a oferta de bens privados (destinados às clientelas) em detrimento da oferta de bens públicos (Carvalho, 2003). Na literatura corrente, essa forma de ação política é caracterizada como clientelista (Almeida e Lopez, 2012), contribuindo para o surgimento de um "mercado de votos" (Rocha e Barbosa, 2008).

Uma suposição desse modelo é a de que a forte conexão entre representantes e interesses geograficamente concentrados resultante de alguns sistemas eleitorais criaria incentivos para que os representantes atuassem primordialmente no sentido da promoção dos interesses de seu reduto eleitoral, guiando-se pelo paroquialismo, como forma de assegurar sua reeleição. (Rocha e Barbosa, 2008, p. 94).

No entanto, nem todos os partidos e candidatos possuem os recursos necessários para adotar uma estratégia puramente individualista, sendo que a "compra" de votos requer o acesso ao dinheiro e a outros recursos. Alguns políticos podem, então, assumir como alternativa de campanha a adoção de políticas programáticas e o apelo aos eleitores que ou não estão ligados ao sistema clientelista ou que o rejeitam (Samuels, 1997). O voto assumiria aqui valores universalistas, sendo o resultado da socialização e do pertencimento a determinados grupos, ao contrário do que ocorre nas relações clientelistas, em que o voto se aproxima da expressão de interesses materiais individuais (Ferraz, 2009). 
Embora a ideia de base eleitoral não esgote um conceito definido, ela delimita uma unidade geográfica ou administrativa na qual o candidato obteve alguma votação e para a qual se espera que o político retorne e dirija sua atividade de representante (Bezerra, 1999, p. 103). No entanto, a quantidade de votos obtida em cada município é um critério que os distingue e os hierarquiza quanto à atenção que é dada pelo político (Bezerra, 1999, p. 103). A literatura aponta que as regiões do estado onde o governante recebeu maior votação são visitadas com mais frequência e recebem maior quantidade de recursos (Bezerra, 1999, p. 103), o que pode contribuir com a manutenção e ampliação desses redutos eleitorais em benefício do governante.

\section{I.I O papel do candidato, do partido e da coligação na arena eleitoral}

O sistema eleitoral brasileiro é conhecido por estimular o personalismo, em que se atribui grande importância à figura do candidato, que, uma vez eleito, pode ter maior sucesso caso venha a concorrer à reeleição. Quer-se dizer que os eleitores, muitas vezes, desvinculam o nome do candidato de sua filiação partidária ou de seus aliados políticos e, por isso, caso esse político encabece uma tentativa à reeleição, tem maiores chances de vitória consecutiva em comparação à tentativa de reeleição de apenas partidos ou coligações não encabeçadas pelo partido que estava no poder.

Samuels (1997) denomina os sistemas eleitorais que contribuem para uma política eleitoral individualista de "centrados do candidato" (Samuels, 1997). Os políticos ao fazerem uma campanha eleitoral focada na sua autoimagem tentam se diferenciar dos demais concorrentes. Sabendo da fragilidade dos partidos políticos na arena eleitoral (Kinzo, 2005), os eleitores, ao votarem, tendo em vista o candidato em particular, normalmente entendem isso como uma forma de manifestar apoio pessoal (Samuels, 1997).

Sabendo que as regiões e os municípios com os quais o político mantém relações mais intensas são aqueles que formam bases eleitorais onde se obteve votações mais expressivas (Bezerra, 1999, p. 103), a reeleição do candidato funcionaria como uma forma de premiação ou punição pelo desempenho dele no primeiro mandato (ou do partido político), de modo que elegendo outro 
candidato do mesmo partido se tem a garantia de continuidade. Assim, o modelo de accountability envolveria um elemento retrospectivo de avaliação dos que estão no poder (Nicolau, 2006, p. 710).

Entretanto, a preponderância do candidato não significa que partidos políticos não possam desempenhar um papel importante na esfera eleitoral. Os partidos políticos são responsáveis por estruturar e organizar a competição eleitoral e têm a possibilidade de se colocar em primeiro plano e tomar para si a tarefa de conquistar votos apelando, por exemplo, para a identificação ideológica dos eleitores ou, e principalmente, para a avaliação retrospectiva do que foi feito em seu governo.

Porém, a literatura brasileira não é muito otimista com relação à efetividade do papel que os partidos políticos desempenham nas eleições. O Brasil tem uma das maiores taxas de volatilidade eleitoral do mundo, ou seja, a distribuição do apoio eleitoral entre os partidos difere muito entre uma eleição e a posterior (Nicolau, 1998; Kinzo, 2005). Isso evidencia que "os partidos não conseguiram se enraizar junto ao eleitorado, a fim de assegurar um nível razoável de apoio popular" (Kinzo, 2005, 67). Os eleitores analisam e escolhem, então, considerando prioritariamente as candidaturas individuais, que se tornam o centro das eleições. A cor partidária, de início, parece estar para o eleitor em segundo plano.

A tentativa da permanência no poder de um partido que não encabeça uma eleição, mas se insere em uma coligação, em uma situação hipotética, também não parece ter um contexto favorável, tendo em vista a não identificação instantânea do partido ou do candidato, o que dá a impressão da formação de um contexto novo de competição política. Pouca informação é passada ao eleitor sobre as coligações e, por isso, o mesmo não dispõe de uma referência relativa à coligação governista que justifique o seu voto nela. Logicamente, a permanência de um partido no poder por meio da coligação da qual faz parte pode ocorrer, mas ela não poderá ser atribuída, em um primeiro momento, ao partido ou ao candidato que venceu na eleição anterior.

Os estímulos para que um partido monte uma coligação a fim de concorrer a uma eleição podem ser vários, e a literatura brasileira sobre coligações comumente apresenta dois como os mais relevantes. De um lado, a inserção do partido em uma coligação pode 
estar ligada a um interesse partidário individual, em que o partido vê a formação de uma aliança partidária como uma estratégia política racional que trará benefícios no contexto eleitoral. De outro, a construção de coligações pode apontar para a manutenção de clãs políticos, "sinalizando aos demais membros do campo político afinidades com determinados grupos e afastamento de outros" (Machado e Miguel, 2008, p. 42). Em geral, as coligações servem mais como uma referência para os próprios políticos e menos como uma orientação aos eleitores.

\section{Espacialidade do voto}

Conforme aponta Bezerra (1999), a identificação das bases eleitorais de um candidato é relevante na medida em que para elas se direciona a maior parte da sua atividade enquanto político. A importância atribuída às bases, no caso do poder executivo estadual, vem do fato de que a sua manutenção significa maiores possibilidades de conquistar uma reeleição. A verificação da concentração ou da dispersão geográfica da votação no estado para o candidato eleito é importante para identificar as localidades onde ele possui ou não força política.

Em que pese o voto ser um ato individual, para o entendimento da concentração da votação em determinado lugar é necessário abordar a teoria do contextualismo geográfico, segundo a qual o comportamento dos eleitores é influenciado pelo ambiente sócio geográfico, seja pelas redes de interação social existentes ou pela semelhança de experiências às quais os habitantes de uma região estão submetidos (Soares e Terron, 2008, p. 275). Segundo essa linha de pensamento, a política não pode ser compreendida desconsiderando-se o contexto no qual ocorre e as condições em que se encontram os indivíduos (Lazarsfeld et al., 1970; Soares e Terron, 2008). Em oposição a essa perspectiva está a teoria da escolha racional, que tem o indivíduo como ator racional que procura maximizar seus benefícios agindo de acordo com seu interesse individual.

Nesse sentido, entende-se que os indivíduos são mais afetados por questões próximas à sua realidade do que por questões gerais como a ideologia (Converse, 1964), sendo que pessoas com realidades semelhantes, o que é mais comum quando 
vivem próximas geograficamente, estão predispostas, no cenário eleitoral, a votar também de modo semelhante. Em suma, atenta-se para o fato de que a existência de referências comuns entre os indivíduos pode interferir na ação política dos mesmos, direcionando-a em um mesmo sentido. Esse compartilhamento de referências pode advir tanto da interação social entre os indivíduos quanto do pertencimento a determinado contexto geográfico.

Conforme citado anteriormente, a teoria aponta que uma das estratégias que o governador candidato à reeleição pode utilizar para sustentar ou expandir suas bases eleitorais a fim de se manter no poder é a distribuição de benefícios para áreas localizadas do estado, geralmente as que, na eleição anterior, mostraram votação significativa nele. Os aspectos composicional e geográfico entram em cena no modelo distributivista quando os dados empíricos sobre a geografia eleitoral evidenciam que as políticas distributivistas têm maior efeito nas regiões de baixo desenvolvimento socioeconômico que, por sua situação, possuem maior dependência do governo e de suas intervenções (Borges et al., 2010, p. 4).

Os atributos demográficos e populacionais dos municípios também são importantes na aproximação que o governador tem com os prefeitos visando sua reeleição. Áreas rurais e/ou pequenos municípios do estado exemplificam onde os governadores podem, em teoria, contar com o auxílio de lideranças locais na mobilização a seu favor do eleitorado ali residente (Borges et al., 2010, p. 4). Os líderes municipais funcionam, nesse sentido, como intermediários na relação entre governo do estado e eleitores, pois têm um grau de proximidade maior com os últimos e, por isso, têm maior facilidade de mobilizá-los politicamente. Nesse sentido, a localização da capital e dos municípios interioranos no estado pode em muito contribuir com a análise espacial e possibilitar estudos explicativos posteriores. A capital funciona como uma referência para a análise da distribuição geográfica da diferença da votação entre duas eleições no cenário de reeleição. A partir dela é possível falar em interiorização dos votos, quando se observa que os municípios que votam em peso no candidato se encontram no interior do estado, onde geralmente está a população mais pobre e esparsamente povoada. 


\section{Metodologia de pesquisa}

O foco da pesquisa é verificar se a distribuição dos votos entre uma eleição e a seguinte para o cargo de governador aponta para uma possível estabilidade dos redutos eleitorais, influenciando, com isso, a reeleição do candidato, do partido ou da "coligação" que estava no poder. Ressalta-se que quando se fala em reeleição de coligação, se considera que o partido que foi eleito na eleição anterior não encabeça uma tentativa à reeleição, mas faz parte da aliança de partidos que formam a coligação vitoriosa na eleição seguinte.

O objeto de estudo consiste nas votações recebidas por uma amostra de candidatos, partidos e coligações que foram reeleitos nos estados que comporão uma amostra, considerando o período das quatro últimas eleições - 1998, 2002, 2006 e 2010. A fim de montar a amostra de estados, primeiramente foram organizados os dados relativos ao cargo de governador nas eleições de 1998, 2002, 2006 e 2010, considerando o candidato vitorioso, seu partido, sua votação percentual, o turno no qual foi eleito e a coligação a qual ele pertencia. Com os dados retirados do site do Tribunal Superior Eleitoral (TSE), isso foi feito para a totalidade dos estados brasileiros mais o Distrito Federal em cada uma das eleições citadas. Ressalta-se que, para fins de organização dos dados e análise, foram utilizados pares de eleições, a saber: 1998-2002, 2002-2006, e 2006-2010.

Com isso, foi possível observar um quadro geral dos candidatos vitoriosos nas quatro eleições e verificar, por estado, se houve reeleição. A partir disso, elaborou-se uma tabela com todos os estados e o DF contendo o que se denominou de cenários, que apontavam para a reeleição ou não de candidato, partido ou coligação. Tomando como base sempre a eleição anterior nos três pares de eleições considerados, foi atribuído, por estado, um cenário por ano eleitoral.

Observaram-se cenários de reeleição de partido e candidato ${ }^{1}$, candidato, partido e coligação bem como cenários em que houve a não reeleição de partido e candidato e a não reeleição de partido. Além

1. No caso em que partido e candidato foram reeleitos, priorizou-se o candidato no cenário de reeleição. 
disso, cenários em que o partido não encabeçou uma candidatura, mas estava coligado e em que nem o partido nem o candidato tentaram reeleição.

Somando-se o objetivo do estudo com a existência na arena eleitoral de três atores políticos - candidato, partido e coligação - foi composta a amostra de estados. Foram escolhidos tendo em vista os cenários referentes à reeleição, priorizando os estados com maior número de municípios, visto que quanto maior o número de municípios, maior a possibilidade de se verificar diferentes cenários e a dinâmica geográfico-eleitoral no estado. A tabela 1 mostra os estados e as eleições que foram selecionados para os cenários de reeleição de candidato, partido e coligação.

Tabela I. Estados selecionados para os cenários de reeleição de candidato, partido e coligação

\begin{tabular}{|c|c|c|c|c|c|c|}
\hline & CAND & DATO & PART & IDO & COLIGA & ÇÃO \\
\hline & Estado & Eleição & Estado & Eleição & Estado & Eleição \\
\hline & Alagoas & 1998-2002 & Bahia & 1998-2002 & Amazonas & $1998-2002$ \\
\hline$\frac{0}{9}$ & Bahia & $2006-2010$ & Ceará & 1998-2002 & Espírito Santo & $2006-2010$ \\
\hline 1 & Ceará & $2006-2010$ & Maranhão & $1998-2002$ & Goiás & $2002-2006$ \\
\hline 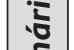 & Goiás & 1998-2002 & Minas Gerais & $2006-2010$ & Paraíba & $2006-2010$ \\
\hline Font & e:Pellabontação & lal 29802002 & ar ธ̃̃odossildad & $2988-28 \theta 2<$ & Nww.tBieujus.br> & $2006-2010$ \\
\hline & Pernambuco & $2006-2010$ & São Paulo & $2006-2010$ & Santa Catarina & $2006-2010$ \\
\hline
\end{tabular}

O próximo passo foi extrair do site do TSE as votações por município relativas aos estados selecionados. Conforme observado, para cada estado foram analisadas as votações de um par de eleições referente à reeleição de candidato, partido ou coligação. A porcentagem de votos por município do candidato, partido ou coligação vitorioso foi utilizada como unidade de análise e o resultado da comparação entre as distribuições de votos das duas eleições consideradas foi conseguido pela diferença entre a porcentagem de votos em um município de uma eleição e a anterior.

$$
\operatorname{Dif}(\text { votmun })=\% \operatorname{Vot}(\text { eleição } t)-\% \operatorname{Vot}(\text { eleição } t-4)
$$


Desse modo, por meio dos valores da diferença entre as votações, foi possível notar se nos municípios que compunham um estado havia um aumento, uma diminuição ou ainda uma estabilidade da proporção de votos recebida de uma eleição para outra.

A classificação dos valores que iriam ser considerados como aumento, diminuição ou estabilidade da votação entre duas eleições nos municípios do estado analisado foi feita a partir da escala construída na legenda dos mapas de quartil que foram elaborados. A escala considerou como valores de diminuição (negativos) aqueles entre -50 e -5 pontos percentuais, localizados no primeiro quartil; como valores de estabilidade (central) aqueles de $-4,9$ a 5 pontos percentuais dispostos no segundo quartil; e, como valores de aumento (positivos) aqueles entre 5,1 e 50 pontos percentuais, que compunham o terceiro quartil.

\section{Distribuição da votação para o cargo de governador nos municípios no caso de reeleição}

\section{I Resultados quantitativos para a reeleição do candidato}

Os dados referentes à reeleição do candidato nos estados (tabela 2) são claros quanto ao crescimento da votação no candidato governista na maioria dos municípios de uma eleição para outra.

Tabela 2. Disposição percentual dos municípios em torno da variação da votação observada no cenário de reeleição de candidato nos estados selecionados

\begin{tabular}{lcccccc}
\hline \multicolumn{7}{c}{ Candidato - reeleito } \\
\hline \multirow{2}{*}{ Eleições } & $\mathbf{1 9 9 8 -}$ & $\mathbf{1 9 9 8 -}$ & $\mathbf{2 0 0 6 -}$ & $\mathbf{2 0 0 6 -}$ & $\mathbf{2 0 0 6 -}$ & $\mathbf{1 9 9 8 -}$ \\
& $\mathbf{2 0 0 2}$ & $\mathbf{2 0 0 2}$ & $\mathbf{2 0 1 0}$ & $\mathbf{2 0 1 0}$ & $\mathbf{2 0 1 0}$ & $\mathbf{2 0 0 2}$ \\
UF & Goiás & Alagoas & Pernambuco & Bahia & Ceará & Pernambuco \\
Positivo & $45,12 \%$ & $48,04 \%$ & $89,19 \%$ & $77,22 \%$ & $28,26 \%$ & $69,19 \%$ \\
Central & $36,18 \%$ & $23,53 \%$ & $10,27 \%$ & $14,87 \%$ & $17,39 \%$ & $18,92 \%$ \\
Negativo & $18,70 \%$ & $28,43 \%$ & $0,54 \%$ & $7,91 \%$ & $54,35 \%$ & $11,89 \%$ \\
\hline
\end{tabular}

Fonte: Elaboração da autora a partir dos dados do TSE <www.tse.jus.br>

Embora não possam ser feitas generalizações, os dados amostrais indicam que o sucesso de reeleição quando o partido lança o candidato que foi vitorioso na eleição anterior é significativamente positivo, o que corrobora com a literatura acerca da preponderância do voto 
personalista no Brasil. Essa ideia se torna ainda mais evidente quando se analisam os dados relativos à reeleição do partido governista quando ele lança uma candidatura diferente da eleição anterior.

O Ceará no par de eleições 2006-2010 é o único caso da amostra que não segue o padrão observado. Embora o candidato governista tenha sido reeleito, a porcentagem de municípios onde decresceu a proporção de votos de uma eleição para outra foi alta quando comparada às porcentagens dos municípios onde a votação aumentou ou permaneceu estável. Não obstante a retração da base eleitoral nesse caso, uma possível explicação para a reeleição do candidato governista pode ser encontrada quando se analisa o tamanho populacional dos municípios cearenses onde a votação foi positiva e negativa. A hipótese é de que a votação decresceu nos municípios de baixa população, aumentando ou permanecendo estável, no entanto, nos municípios mais populosos.

\subsection{Resultados quantitativos para a reeleição do partido}

Na tabela 3 observa-se que na maioria dos municípios em que o partido do governo estadual tentou reeleição com outra candidatura houve um decréscimo na votação. Em mais de 50\% dos municípios dos estados do Ceará, Maranhão, Bahia, São Paulo (2006-2010) e Minas Gerais houve queda na votação para o partido. Novamente, a explicação para a reeleição do partido mesmo com diminuição da votação na maioria dos municípios está no tamanho populacional daqueles onde a votação cresceu ou ficou estável.

Tabela 3. Disposição percentual dos municípios em torno da variação da votação observada no cenário de reeleição de partido nos estados selecionados

\begin{tabular}{lcccccc}
\hline \multicolumn{7}{c}{ Partido - reeleito } \\
\hline \multirow{2}{*}{ Eleições } & $\mathbf{1 9 9 8 -}$ & $\mathbf{1 9 9 8 -}$ & $\mathbf{1 9 9 8 -}$ & $\mathbf{2 0 0 6 -}$ & $\mathbf{1 9 9 8 -}$ & $\mathbf{2 0 0 6 -}$ \\
UF & $\mathbf{2 0 0 2}$ & $\mathbf{2 0 0 2}$ & $\mathbf{2 0 0 2}$ & $\mathbf{2 0 1 0}$ & $\mathbf{2 0 0 2}$ & $\mathbf{2 0 1 0}$ \\
Positivo & $19,02 \%$ & $3,69 \%$ & $4,32 \%$ & $1,40 \%$ & $40,00 \%$ & $2,81 \%$ \\
Central & $17,93 \%$ & $15,21 \%$ & $22,54 \%$ & $16,74 \%$ & $20,00 \%$ & $14,30 \%$ \\
Negativo & $63,04 \%$ & $81,11 \%$ & $73,14 \%$ & $81,86 \%$ & $40,00 \%$ & $82,88 \%$ \\
\hline
\end{tabular}

Fonte: Elaboração da autora a partir dos dados do TSE <www.tse.jus.br> 
O único caso que destoa dos demais é São Paulo entre as eleições de 1998 e 2002, em que, curiosamente, houve votação positiva e negativa na mesma porcentagem de municípios. Conforme será indicado mais a frente a partir da comparação dos mapas das votações nos dois períodos eleitorais, nesse caso em particular, ao que parece, ocorreu uma inversão significativa das bases eleitorais do partido, isto é, onde o partido tinha baixa votação passou a ter votação expressiva e vice-versa.

A porcentagem de municípios que permaneceram estáveis (centrais) quanto à votação entre uma eleição e outra, tanto no caso da reeleição do candidato, quanto da reeleição do partido, quando olhada por si só, não se mostrou um dado importante para a manutenção no poder do candidato ou do partido. Em todos os casos nos dois conjuntos de dados (candidato e partido), a porcentagem de municípios que apresentaram certa estabilidade na votação ficou abaixo dos $37 \%$. No entanto, a porcentagem dos municípios estáveis é relevante quando analisada tendo em vista o tamanho da população dos municípios em questão. Como já explicitado, a estabilidade observada nos municípios populosos pode ajudar na explicação da reeleição do candidato ou do partido nos estados onde a votação foi negativa na maior parte dos municípios.

Com efeito, a disposição percentual dos municípios em torno da variação da votação nos casos em que houve a reeleição do candidato e naqueles em que ouve a reeleição do partido mostra a tendência do eleitor brasileiro em votar considerando a figura do candidato, deixando em segundo plano as referências partidárias. Há maior possibilidade de sucesso na manutenção do poder executivo estadual quando o partido lança a mesma candidatura do que quando ele indica outra pessoa para o cargo de governador.

Confiar na manutenção das bases eleitorais de uma eleição para a seguinte quando o partido tenta a reeleição se mostra muito arriscado para garantir a vitória, mesmo que o governo procure mantê-las por meio de transferências financeiras, aproximações com os prefeitos municipais e demais líderes locais ou outros incentivos. Desse modo, faz-se necessário procurar ampliar a votação, o que, de acordo com os dados da amostra, é mais propício quando o mesmo candidato concorre à reeleição. 
4.3 Resultados quantitativos para a reeleição do partido inserido em uma coligação

A tabela 4, que mostra resultados amostrais da manutenção do partido no poder por meio de uma coligação, diferentemente das tabelas 2 e 3, não apresenta padrões.

Tabela 4. Distribuição percentual dos municípios em torno da variação da votação observada no cenário de reeleição de partido em uma coligação nos estados selecionados

\begin{tabular}{|c|c|c|c|c|c|c|}
\hline \multicolumn{7}{|c|}{ Partido-coligação - reeleito } \\
\hline Eleições & $\begin{array}{l}2006- \\
2010\end{array}$ & $\begin{array}{l}2006- \\
2010\end{array}$ & $\begin{array}{l}1998- \\
2002\end{array}$ & $\begin{array}{l}\text { 2006- } \\
2010\end{array}$ & $\begin{array}{l}2002- \\
2006\end{array}$ & $\begin{array}{l}2006- \\
2010\end{array}$ \\
\hline UF & Paraíba & Piauí & Amazonas & $\begin{array}{c}\text { Santa } \\
\text { Catarina }\end{array}$ & Goiás & $\begin{array}{c}\text { Espírito } \\
\text { Santo }\end{array}$ \\
\hline Positivo & $21,24 \%$ & $45,54 \%$ & $67,74 \%$ & $18,09 \%$ & $47,56 \%$ & $12,82 \%$ \\
\hline Central & $36,73 \%$ & $28,13 \%$ & $22,58 \%$ & $41,64 \%$ & $39,84 \%$ & $60,26 \%$ \\
\hline Negativo & $42,04 \%$ & $26,34 \%$ & $9,68 \%$ & $40,27 \%$ & $12,60 \%$ & $26,92 \%$ \\
\hline
\end{tabular}

Fonte: Elaboração da autora a partir dos dados do TSE <www.tse.jus.br>

Dos estados que compunham a amostra, Piauí, Amazonas e Goiás tiveram na maioria dos municípios uma expansão da votação, ao passo que a Paraíba apresentou um cenário expressivo de votação negativa de uma eleição para outra. Já Santa Catarina e Espírito Santo, nas eleições consideradas, tiveram um maior número de municípios que permaneceram estáveis quanto à votação na coligação em comparação com a votação que tinha tido o partido em um ano eleitoral anterior.

Sabendo da escassez de estudos no Brasil sobre a influência que coligações políticas têm no comportamento dos eleitores, os dados empíricos encontrados por esse estudo contribuem para a sustentação dessa lacuna na literatura, de modo que não é possível observar se a dinâmica de coligações contribui ou não para a manutenção de bases eleitorais. Talvez estudos mais aprofundados sobre coligações que envolvam outras variáveis do cenário político-eleitoral tenham maior sucesso em desvendar se há e qual é a contribuição delas para a escolha do voto pelo eleitorado. 
Dos estados que compunham a amostra, Piauí, Amazonas e Goiás tiveram na maioria dos municípios uma expansão da votação, ao passo que a Paraíba apresentou um cenário expressivo de votação negativa de uma eleição para outra. Já Santa Catarina e Espírito Santo, nas eleições consideradas, tiveram um maior número de municípios que permaneceram estáveis quanto à votação na coligação em comparação com a votação que tinha tido o partido em um ano eleitoral anterior.

Sabendo da escassez de estudos no Brasil sobre a influência que coligações políticas têm no comportamento dos eleitores, os dados empíricos encontrados por esse estudo contribuem para a sustentação dessa lacuna na literatura, de modo que não é possível observar se a dinâmica de coligações contribui ou não para a manutenção de bases eleitorais. Talvez estudos mais aprofundados sobre coligações que envolvam outras variáveis do cenário político-eleitoral tenham maior sucesso em desvendar se há e qual é a contribuição delas para a escolha do voto pelo eleitorado.

\section{Distribuição geográfica da diferença da votação entre eleições nas situações de reeleição do candidato, do partido e do partido inserido em coligação}

Para os fins deste estudo, será considerada apenas a dimensão horizontal da geografia dos votos, que consiste na proximidade ou no distanciamento das localidades onde houve votação significativa. No entanto, ressalta-se que os dados da pesquisa aqui realizada não tratam da observância dos municípios onde o candidato ou o partido tiveram maioria de votos, mas tratam da variação da proporção de votos de uma eleição para outra.

Considerando o vetor concentração, pode-se falar que a votação é concentrada ou dispersa. A primeira é o caso em que um candidato ou partido tem votação expressiva em um grupo de municípios próximos. Já a votação dispersa é aquela em que os municípios onde se teve votação significativa são espalhados pelo estado. Conforme apontam Soares e Terron (2008), o padrão espacial de uma votação dispersa é semelhante à figura de um mosaico, em que não existem territorialmente muitas regiões homogêneas em relação à escolha eleitoral.

Além dos fatores concentração e dispersão, a análise dos mapas levou em consideração a localização geográfica capital-interior, conforme discussão teórica feita anteriormente. Nos mapas, a capital dos estados selecionados está identificada com um ponto de cor preta. 
Os mapas que se seguem indicam a diferença de votação entre duas eleições no caso de reeleição do candidato, do partido ou da coligação a qual o partido vitorioso na última eleição pertencia. $\mathrm{O}$ intuito é verificar qual é a dinâmica espacial dos votos para essas três situações de reeleição e se há alguma diferença entre elas. Para que as comparações da distribuição territorial do eleitorado entre esses três cenários sejam observadas com mais facilidade, os mapas foram organizados em três conjuntos, tendo em vista as três situações de reeleições já citadas.

\section{I Diferença da votação considerando a reeleição do candidato}

\section{Alagoas (1998-2002)}

Conforme mostra abaixo o mapa de Alagoas, comparando-se a votação recebida pelo candidato reeleito em 2002 com a de 1998, a quantidade de municípios onde a votação cresceu ou permaneceu estável é maior do que onde a votação decaiu. Percebe-se que a votação foi dispersa pelo estado. No entanto, a capital e os municípios em volta são regiões onde o a votação foi negativa. Nesse caso, a capital não representa um bastião eleitoral de peso para o candidato, ao contrário do que se observa nas regiões do interior e nas fronteiriças do estado.

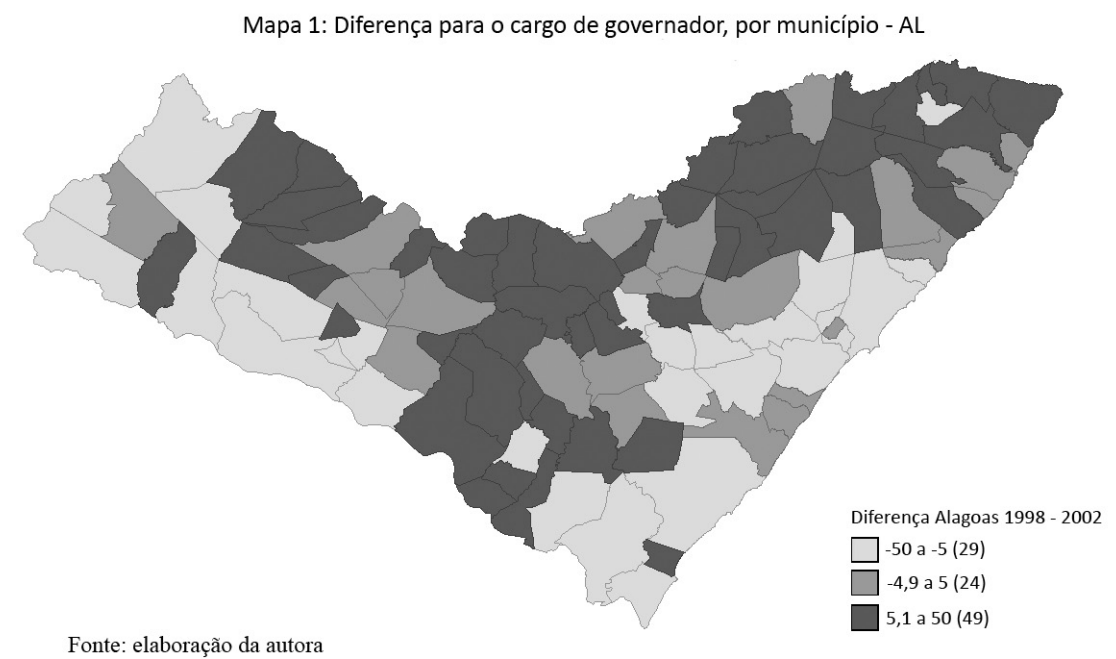


Goiás (1998-2002)

Em Goiás se observa também uma dispersão das regiões onde a votação aumentou ou permaneceu estável. Pelo fato de Goiás possuir maior quantidade de municípios quando comparado a Alagoas, pode-se dizer que na comparação entre os dois mapas Goiás mostra maior dispersão na votação. Observa-se ainda que especificamente a capital, Goiânia, foi uma região onde a votação decresceu de uma eleição para outra.

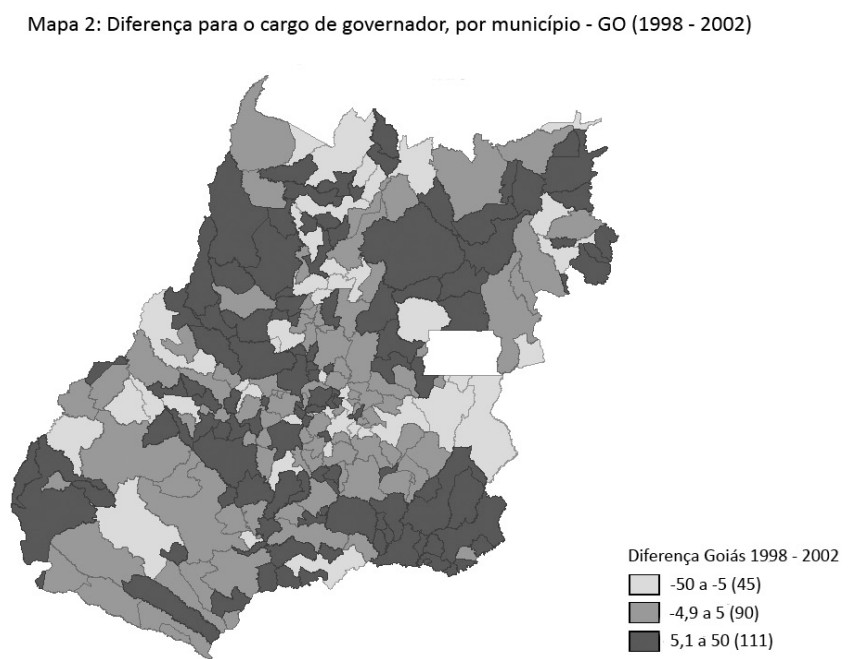

Fonte: elaboração da autora

Pernambuco (1998-2002)

Na comparação entre 1998 e 2002 em Pernambuco, é possível observar uma dispersão da votação, de modo que os municípios nos quais o candidato conseguiu maior votação estão espalhados pelo estado. Chama a atenção o fato de que a capital Recife e os municípios próximos a ela são localidades onde a votação decaiu entre os períodos eleitorais, bem como a existência de um grupo de municípios ao centro estado nos quais a votação também decresceu. 


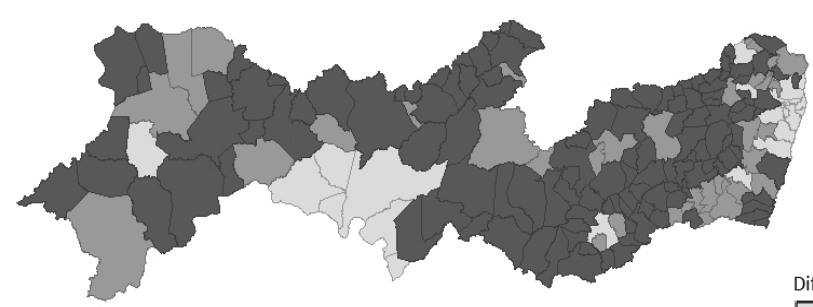

Diferença Pernambuco 1998 - 2002

$\square-50$ a -5 (22)

$\square-4,9$ a 5 (35)

Fonte: elaboração da autora

5,1 a $50(128)$

\section{Pernambuco (2006-2010)}

Já no mapa de Pernambuco relativo às eleições 2006-2010, se observa que a votação foi mais dispersa, de maneira que as regiões onde houve crescimento da votação se espalham por todo o estado. Não se pode falar, nesse caso, de uma base eleitoral específica, pois apenas um município apresentou votação negativa de uma eleição para outra, de acordo com o modelo de quartis aqui proposto.

Mapa 4: Diferença para o cargo de governador, por município - PE (2006 - 2010)

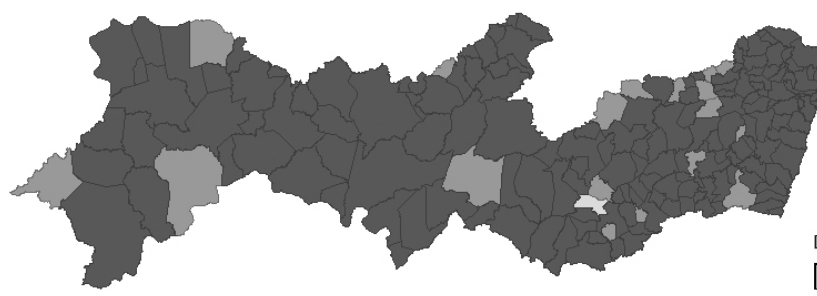

Diferença Pernambuco 2006 - 2010

$\square-50$ a -5 (1)

$-4,9$ a $5(19)$

5,1 a $50(165)$

Fonte: elaboração da autora 
Bahia (2006-2010)

Comparando-se a diferença da votação na Bahia entre 2006 e 2010, se observa que a votação positiva entre as eleições é dispersa por todo o estado. Pelo grau de dispersão da votação pelo estado não é possível falar em bases eleitorais específicas.

Mapa 5: Diferença para o cargo de governador, por município - BA (2006 - 2010)
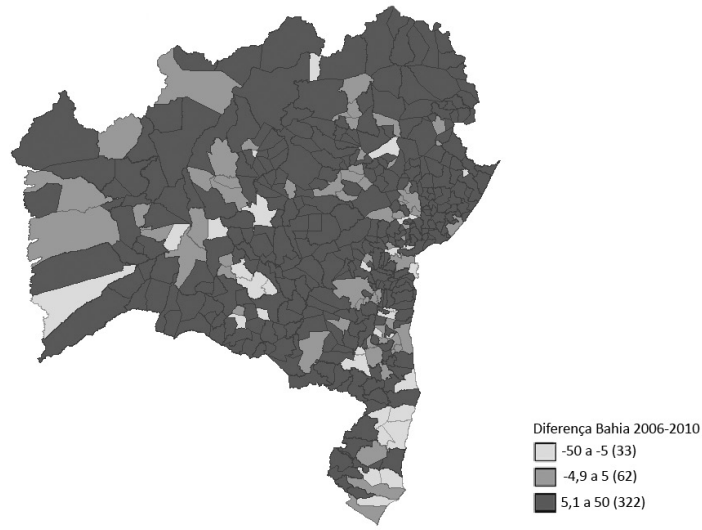

Fonte: elaboração da autora

Ceará (2006-2010)

Entre as eleições de 2006 e 2010 se observa que no Ceará a votação do candidato reeleito foi concentrada, principalmente nos municípios do norte e do sul do estado. Mais especificamente a capital e as regiões próximas a ela, bem como as regiões do interior sul do estado, são onde a diferença da votação foi em benefício do candidato reeleito. Embora não seja possível afirmar, por meio desse mapa ou dos dados coletados, que o candidato reeleito tenha conseguido a maioria dos votos nos municípios de cor escura no mapa frente aos demais concorrentes, é possível inferir que essas regiões são potenciais bases eleitorais do candidato reeleito, uma vez que nelas, de uma eleição para outra, a votação cresceu ou permaneceu estável. A quantidade de municípios onde a diferença da votação foi negativa é expressiva. A reeleição do candidato pode estar relacionada com o tamanho populacional dos municípios 
onde a votação entre os dois períodos eleitorais permaneceu estável ou aumentou.

\section{I.I Conclusões gerais da distribuição geográfica no caso de reeleição do candidato}

Tendo em vista os mapas dos estados selecionados para verificar a dinâmica geográfica da reeleição do candidato, observa-se que em três dos quatro casos analisados se tem dispersão da diferença positiva de votação. A exceção é o estado do Ceará, conforme citado anteriormente. Comparando-se os mapas entre si, percebe-se que alguns estados demonstram maior dispersão na proporção de votos de uma eleição para outra do que os demais. Olhando os mapas individualmente, à exceção do Ceará, as diferenças de votação observadas no candidato reeleito são dispersas e, em sua maioria, se concentram no segundo e no terceiro quartis, que representam valores positivos.

Esses dados corroboram com a literatura que vê o sistema político-eleitoral brasileiro como personalista no sentido de dar maior relevância ao candidato nas campanhas eleitorais em detrimento dos partidos políticos e mais ainda das coligações partidárias. A tendência é, portanto, que o voto dos eleitores seja direcionado ao candidato, o que evidencia um comportamento eleitoral pautado no apoio pessoal do eleitor ao político, deixando em segundo plano fatores mais gerais que podem influenciar o voto como ideologia partidária, políticas pragmáticas, entre outros. Nos estudos de caso realizados, a dispersão observada na reeleição do candidato indica que o partido tem maiores chances de se manter no poder quando lança a mesma candidatura da eleição anterior, de modo que, como mostram os dados, o candidato amplia sua votação por todo o estado e recebe o apoio de grande parte da população.

\subsection{Diferença da votação considerando a reeleição do partido}

\section{Bahia (1998-2002)}

Na Bahia, entre as eleições de 1998 e 2002, se observa uma concentração das regiões onde a votação foi significativa o bastante para reeleger o partido. A reeleição do partido, mesmo considerando o número de municípios nos quais a votação decaiu, pode ser explicada 
analisando a quantidade da população nos municípios em que a votação foi positiva ou permaneceu estável. A hipótese de estudo, que não será avaliada aqui, é a de que a decadência da votação entre as eleições ocorreu nos municípios pequenos em termos populacionais, ao passo que as regiões em que a diferença da votação foi positiva são aquelas com maior população.

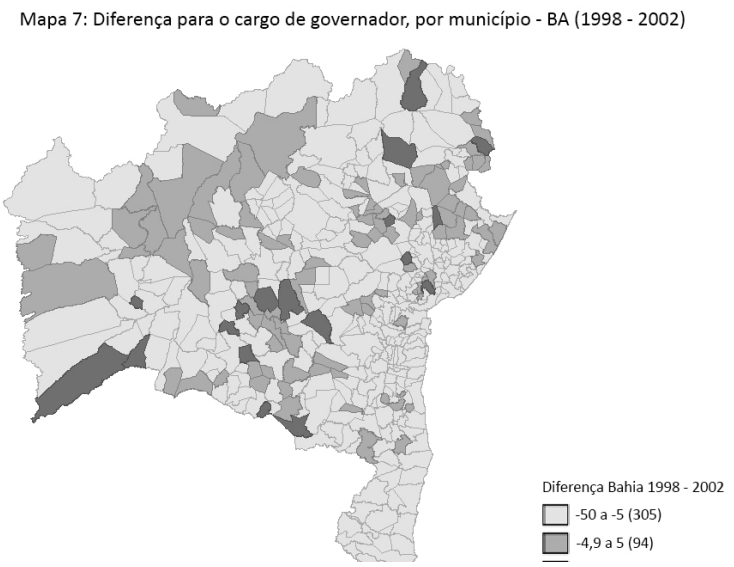

Ceará (1998-2002)

Entre as eleições de 1998 e 2002 se observa que, no Ceará, a reeleição do partido teve votação expressiva concentrada principalmente nos municípios do interior e nos fronteiriços. A reeleição nesse caso foi conquistada pelo partido mesmo com a diminuição da votação na maioria dos municípios, o que novamente aponta para a importância do tamanho da população na análise mais profunda da reeleição.

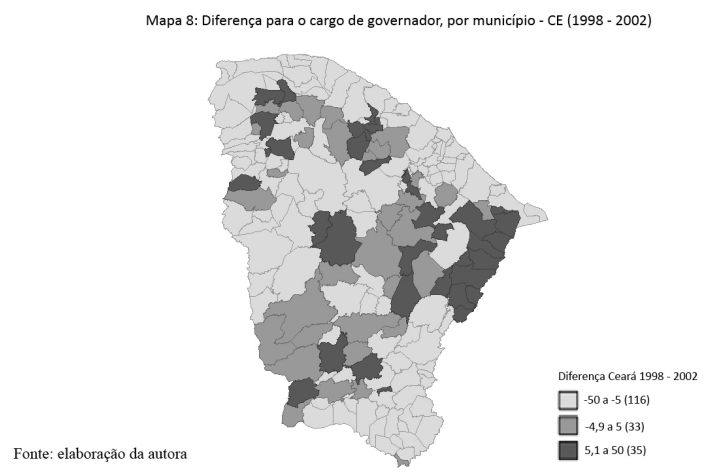


Maranhão (1998-2002)

Entre 1998 e 2002 no Maranhão, em que houve a reeleição do partido, nota-se que a diferença positiva da votação foi concentrada. Os municípios fronteiriços com o Piauí e alguns municípios localizados no centro do estado são regiões onde, diferentemente dos demais municípios nos quais a votação de uma eleição para outra decaiu, o partido reeleito conseguiu manter seu eleitorado ou expandi-lo. Nesse sentido, esses municípios podem ser vistos como bases eleitorais mantidas pelo partido entre as eleições correspondentes.

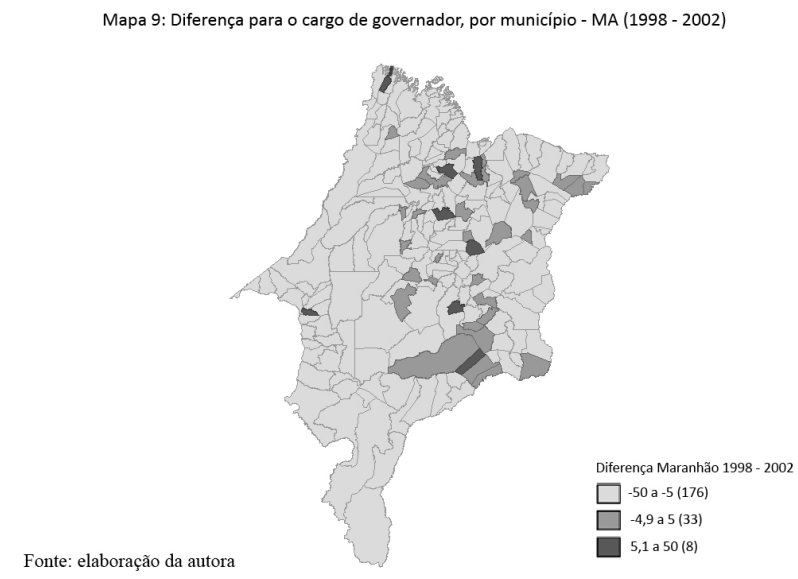

São Paulo (1998-2002)

Comparando-se a votação obtida pelo partido reeleito entre as eleições de 1998 e 2002 no estado de São Paulo, vê-se que o crescimento da votação foi disperso por todo o estado. Atenta-se para uma grande concentração de municípios no sul do estado, onde a votação no partido aumentou entre as eleições. No entanto, não é possível apontar localidades específicas onde existam bases eleitorais, já que por todo o estado houve crescimento positivo da votação no partido reeleito.

O fato interessante ocorrido em São Paulo entre as eleições de 1998 e 2002 foi que o candidato que venceu em 2002, Geraldo Alckmin, era vice-governador em 1998, sendo Mário Covas o governador eleito daquele ano. Com a morte de Covas em 2001, 
Alckmin assumiu o governo do estado, sendo reeleito nas eleições seguintes. No entanto, esse caso foi incluído na reeleição do partido porque, em tese, o candidato eleito para governador em 1998 não foi o mesmo em 2002.

Nesse sentido, não se pode atribuir a "reeleição" de Alckmin para o governo de São Paulo à memória do eleitor em ter depositado seu voto nele, de modo que, embora fosse vice, não encabeçou a candidatura. A sua popularidade se deveu muito mais à sua exposição pública enquanto governador do estado. Nesse sentido, embora Geraldo Alckmin não tenha sido diretamente eleito em 1998, a sua posse em $2001 \mathrm{fez}$ com que ele fosse identificado como representante do estado, o que em muito colaborou para a sua reeleição em 2002, tendo em vista a força política do candidato, como aponta a literatura e os dados sobre a reeleição do candidato aqui apresentados.

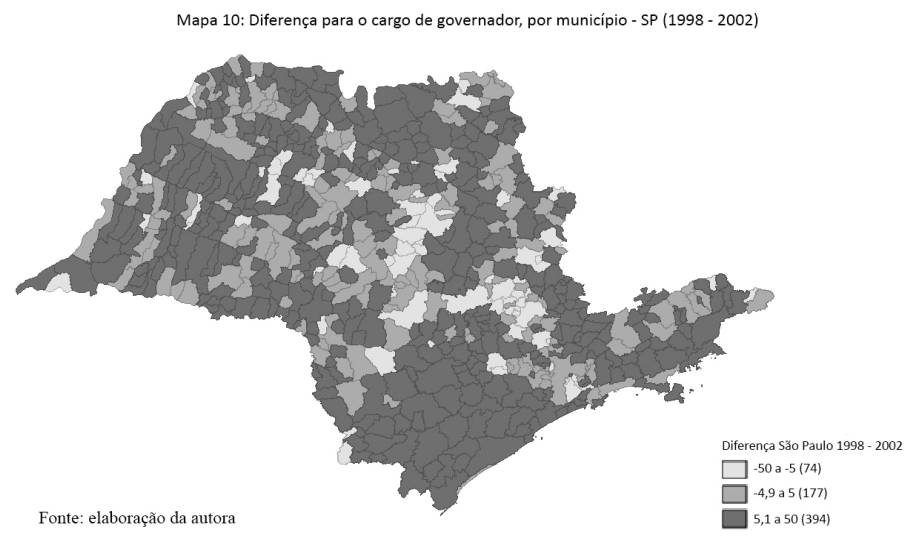

São Paulo (2006-2010)

Observando-se a diferença da votação em São Paulo entre 2006 e 2010, vê-se que a situação é bem diferente do que ocorreu no par de eleições 1998 e 2002. O partido, mesmo reeleito, não manteve na maior parte dos municípios a mesma percentagem de votos da eleição anterior, de modo que se pode inferir que as bases eleitorais não foram sustentadas de uma eleição para outra. A conexão eleitoral no par de eleições considerado se deu de forma diferente do observado no par 1998-2002. A situação do mapa anterior se assemelha 
à situação de candidato reeleito, o que não deixa de ser verdade, na qual a votação é bastante dispersa pelo estado. Já no mapa abaixo, a diferença correspondente à votação estável ou positiva ocorreu em localidades concentradas no estado.

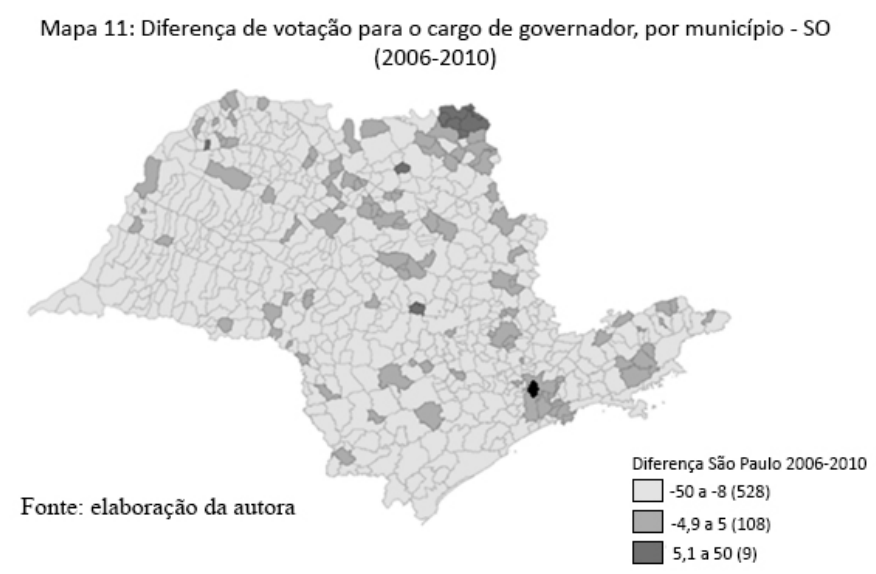

Minas Gerais (2006-2010)

Analisando-se o mapa da diferença da votação em Minas Gerais entre as votações de 2006 e 2010, tem-se que a diferença positiva em benefício do partido reeleito ocorreu em regiões concentradas. Essas regiões são representadas principalmente pelos municípios do interior do estado, relativamente distantes da capital, localidades onde as bases eleitorais foram mantidas, de certa forma.

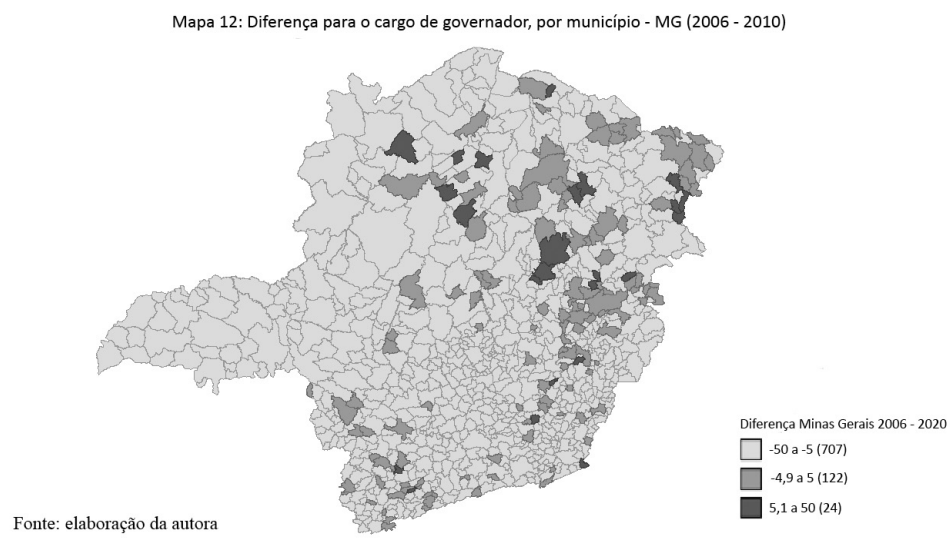




\subsection{Conclusões gerais da distribuição geográfica no caso de reeleição do partido}

Observando os quatro mapas relativos à reeleição do partido, temse que, à exceção de São Paulo entre 1998-2002, os demais estados mostram que a diferença positiva de votação quando o partido tenta a reeleição sem lançar a mesma candidatura da eleição anterior é concentrada em certas regiões dos estados, diferentemente do que acontece com distribuição geográfica observada na reeleição do candidato. Novamente, a comparação dos mapas entre si pode fazer com que algumas distribuições sejam mais concentradas que outras. No entanto, sendo o objetivo identificar padrões a partir dos estudos de casos selecionados, tem-se que a concentração geográfica da diferença positiva de votação consiste em uma característica da reeleição do partido político.

Embora esse apontamento não possa ser generalizado para todas as situações em que o partido tenta se manter no poder, os dados encontrados vão de encontro à literatura, que evidencia a fragilidade dos partidos políticos na arena eleitoral em comparação à figura do candidato. Enquanto o voto personalista exalta a força política do candidato, maximizando o seu apoio eleitoral e consequentemente suas bases eleitorais, a permanência do voto no partido ocorre em regiões específicas, concentradas nos estados, demonstrando que a ideologia ou a avaliação retrospectiva do governo como direcionamento do comportamento eleitoral do cidadão são fatores, na maioria das vezes, secundários, na escolha do voto.

\subsection{Diferença da votação considerando a reeleição do partido a partir da sua inserção em uma coligação partidária}

Amazonas (1998-2002)

No Amazonas se observa que a diferença da votação entre as eleições de 1998 e 2002 foi positiva em grande parte do estado, ou seja, dispersa, na situação em que o partido vitorioso em 1998 se manteve próximo ao poder por sua inserção em uma coligação. Entretanto, não se pode falar na existência de bases eleitorais, uma vez que as regiões com manutenção ou crescimento da votação estão espalhadas de modo uniforme pelo estado. No entanto, a manutenção das bases eleitorais não pode ser atribuída ao partido especificamente, uma vez que, como dito 
anteriormente, pouca informação é passada ao eleitor sobre os partidos que compõem uma coligação partidária. Curiosamente, em Manaus e nos municípios ao seu redor houve diminuição da votação entre as eleições.

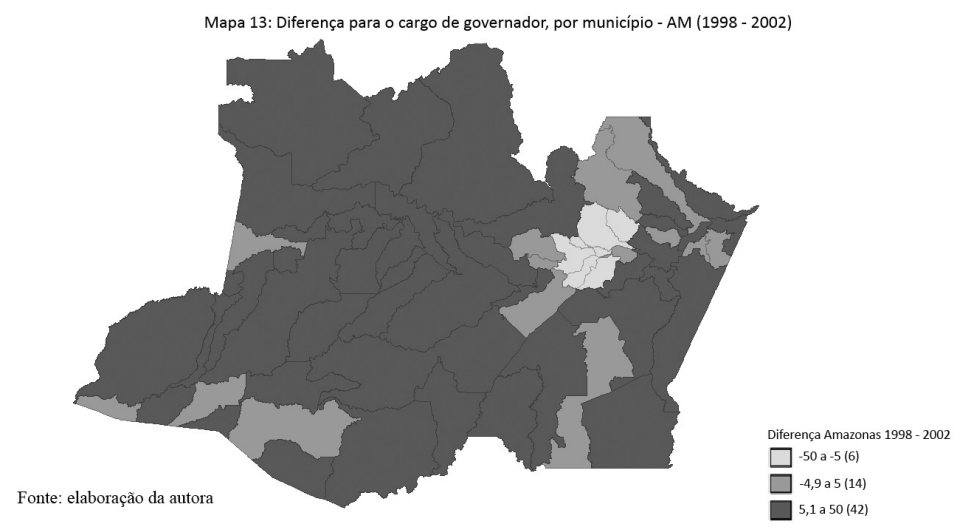

Piauí (2006-2010)

Entre 2006 e 2010 no Piauí se observa que o partido eleito em 2006, mesmo não encabeçando uma eleição, consegue se manter no poder por meio da sua participação na coligação vencedora na eleição seguinte. A comparação entre a votação recebida pelo partido vencedor em 2006 e a coligação vencedora em 2010 revela que em boa parte dos municípios manteve-se a votação obtida pelo partido, de modo que a diferença positiva é dispersa pelo estado.

Mapa 14: Diferença para o cargo de governador, por município - PI (2006 - 2010)

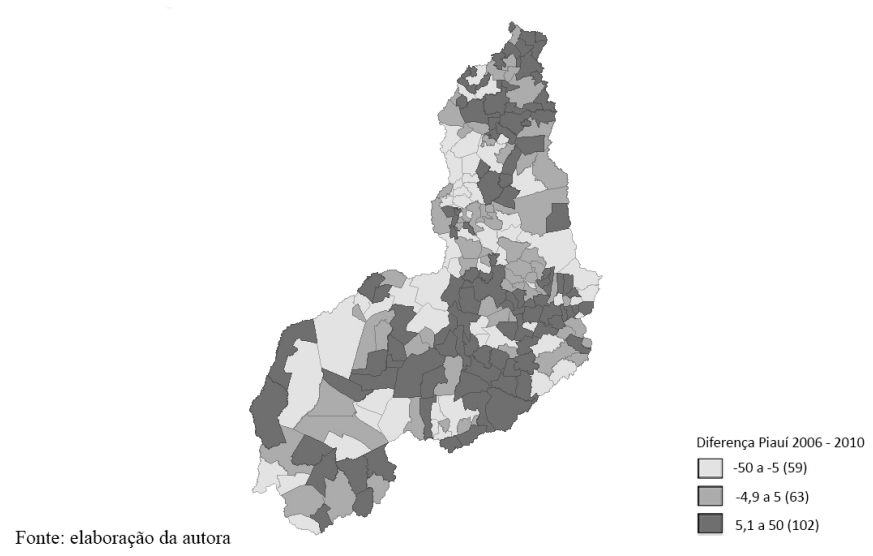


Paraíba (2006-2010)

Na Paraíba observa-se que a diferença da votação no partido (em 2006) e na coligação à qual ele pertencia (em 2010) foi positiva ou manteve-se estável de forma dispersa no estado, em que as três categorias de votação distribuíram-se de forma uniforme. Embora na maioria dos municípios a diferença tenha sido negativa, o número de municípios que permaneceram estáveis foi significativo.

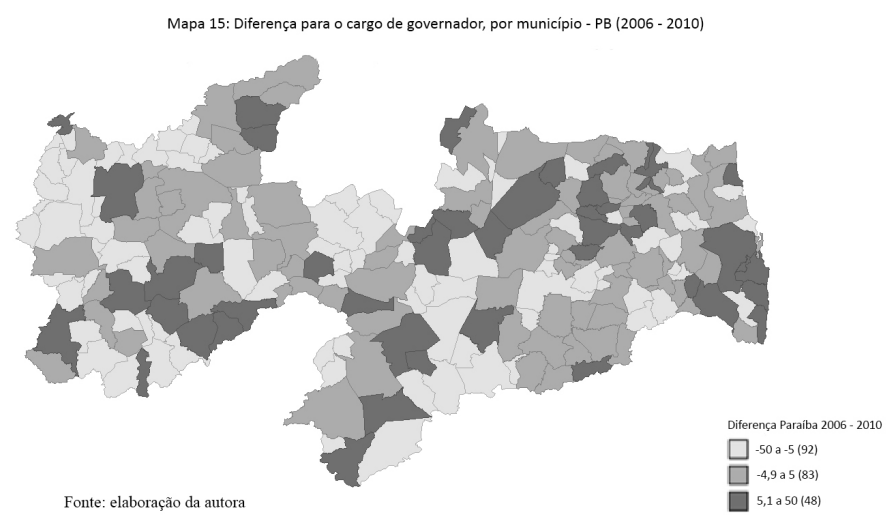

Santa Catarina (2006-2010)

Em Santa Catarina se nota que entre 2006 e 2010 a diferença da votação foi concentrada nos municípios da região central do estado e nos litorâneos.

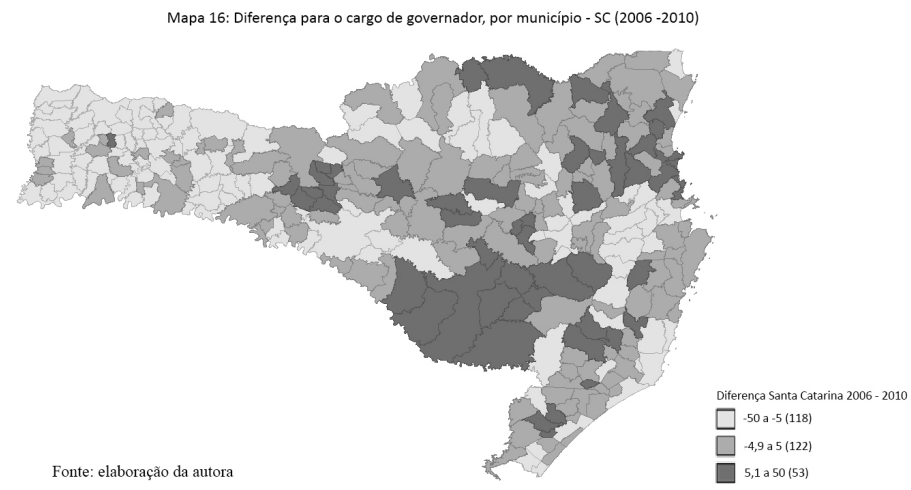


Goiás (2002-2006)

Em Goiás, no par de eleições 2002-2006, o partido vitorioso em 2002 se manteve no poder ao se coligar com outros partidos. Grande parte dos municípios manteve a votação na coligação onde o partido do último governo estava. Nesse sentido, a diferença da votação foi dispersa pelo estado.

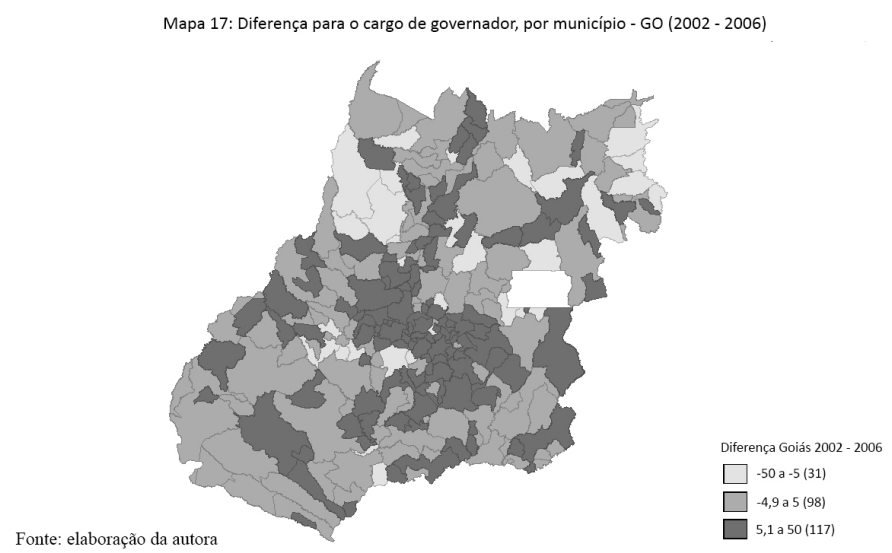

Espírito Santo (2006-2010)

No Espírito Santo nota-se que a diferença da votação entre as eleições de 2006 e 2010 foi dispersa pelo estado, de modo que a diferença positiva pode ser observada principalmente nos municípios localizados no norte e no centro do estado.

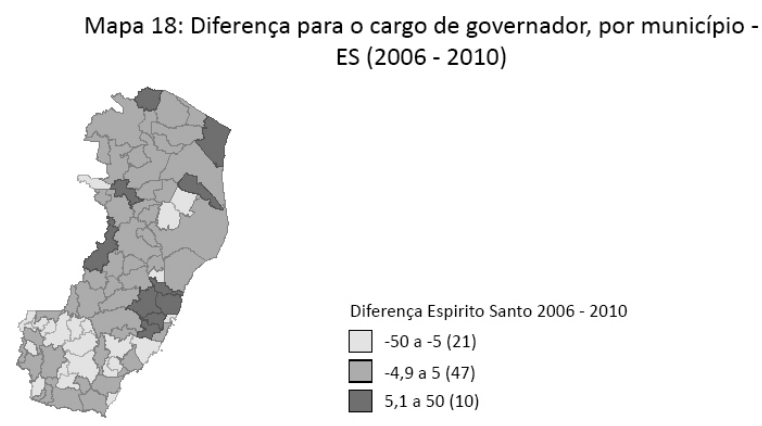

Fonte: elaboração da autora 


\subsection{Conclusões gerais da distribuição geográfica no caso de manutenção do partido no poder mediante sua entrada em uma coligação partidária}

Nos mapas referentes à permanência do partido no poder através da vitória da coligação a qual ele pertencia, nota-se que é difícil estabelecer um padrão geográfico de distribuição da diferença da votação, assim como não é possível falar em padrão quando se analisam os dados quantitativos da distribuição de municípios referentes a esse cenário de "reeleição". Os mapas, nesse caso, são mais relevantes para se analisar a distribuição geográfica da diferença da votação de cada estado, levando em conta suas particularidades. Nesse sentido, o papel das coligações partidárias na arena eleitoral ainda merece atenção e requer estudos mais minuciosos a fim de, pelo menos, minimizar a escassez da literatura existente sobre esse tema, principalmente em um país como o Brasil, onde a composição das coalizões de governo se inicia com a negociação das coligações partidárias no período eleitoral.

\section{Considerações finais}

A compreensão dos fatores que interferem na reeleição de determinado candidato é uma questão central no estudo sobre comportamento eleitoral. Além de aspectos particulares ao eleitor, que englobam as motivações individuais do voto e do não voto, aspectos mais gerais, como a localização geográfica das regiões onde o político recebeu maior quantidade de votos, também são significativos para o tema e, juntamente com os fatores de escala micro, convergem para o entendimento tanto das estratégias políticas utilizadas para se conseguir votos, quanto da tomada de decisão do eleitor.

O presente trabalho foi realizado com o intuito de dar enfoque especialmente à questão geográfica da distribuição dos votos nos casos em que o candidato, o partido ou a coligação permaneceu no poder, sendo vitorioso em eleições consecutivas. O objetivo principal foi verificar se os redutos eleitorais, também chamados de distritos informais, apresentavam alguma estabilidade no sentido de apoio eleitoral que fosse significante para a reeleição do candidato a governador nos estados selecionados.

Embora não possam ser feitas generalizações, os dados dos estudos de casos indicam que o sucesso de reeleição quando o partido 
lança o candidato que foi vitorioso na eleição anterior é significativamente positivo, o que corrobora com a literatura acerca da preponderância do voto personalista no Brasil. Já quando o partido tenta a reeleição, mas não lança a mesma candidatura, há significante decréscimo na proporção de votos recebida pelo novo candidato na maioria dos municípios dos estados analisados, de modo que a sua vitória pode ser explicada pelo tamanho dos municípios onde a votação foi expressiva. No caso da manutenção do partido no poder através de coligações, não é possível observar padrões de aumento ou diminuição da proporção de votos entre dois períodos eleitorais. Nesse sentido, a relevância das coligações no comportamento do eleitorado ainda é uma incógnita.

A análise cartográfica a partir dos vetores de concentração e dispersão da votação indica que, embora não possam ser feitas generalizações, podemos falar em estadualização dos votos quando há a reeleição do candidato, tendo em vista que se verifica em municípios dispersos por todo o estado o crescimento da proporção de votos recebida em uma eleição em comparação com a anterior. Ao passo que na reeleição do partido há certa municipalização dos votos favoráveis, de forma que o aumento da proporção de votos ocorre em municípios concentrados em regiões específicas do estado. Novamente, não é possível descrever padrões no caso da manutenção do partido inserido na coligação que foi vitoriosa.

\section{Referências}

ABRUCIO, F. L. (1994). Os barões da federação. Lua Nova [online], n.33, p. 165-183. ALMEIDA, A.; LOPEZ, F. (2012). Legisladores, captadores e assistencialistas: a representação política no nível local. Rio de Janeiro: Instituto de Pesquisa Econômica Aplicada.

BEZERRA, M. O. (1999). Em nome das "bases": política, favor e dependência pessoal. Rio de Janeiro: Relume-Dumará - NUAP.

BORGES, A.; FERNANDES, A. S. A.; FILHO, A. S. (2010). Repensando a política estadual: competição vertical, políticas sociais e mudança política nos estados brasileiros. Relatório de projeto de pesquisa - Edital Universal do CNPq - 2007. Natal/Brasília.

CARVALHO, N. R. (2003). E no início eram as bases: geografia política do voto e comportamento legislativo no Brasil. Rio de Janeiro: Revan. 
CONVERSE, P. E. (1964). The Nature of Belief Systems in Mass Publics. In: APTER, D. E. Ideology and Discontent. New York: Free Press of Glencoe, p. 206-261.

FERRAZ, S. E. (2009). Voto e Classe: notas sobre alguns estudos recentes. Opinião Pública, v. 15, n. 2, Nov.

KINZO, M. (2005). Os partidos no eleitorado: percepções públicas e laços partidários no Brasil. Revista Brasileira de Ciências Sociais, vol. 20, nº 57.

LAZARSFELD, P.; BERELSON, B.; GAUDET, H. (1970). The nature of personal influence. New York: Columbia University Press, p. 150-158.

MACHADO, C. M.; MIGUEL, L. F. (2008). Padrões de coesão e dispersão: Uma proposta de tipologia para coligações. Teoria \& Pesquisa, vol. 20, n 2, p. 37-58. NEVES, A. C. (2010). Geografia do voto e conexão eleitoral nas eleições de 1994 a 2006 para deputado federal no Piauí. Dissertação de Mestrado: Universidade Federal do Piauí, 2010.

NICOLAU, J (1998). A volatilidade eleitoral nas eleições para a Câmara dos Deputados brasileira (1982-1994). In: Encontro Anual da Associação Nacional de Pós-Graduação em Ciências Sociais, n. 22, Caxambu. Anais... Caxambu: Anpocs.

NICOLAU, J. (2006). O sistema eleitoral de lista aberta no Brasil. Dados [online], vol.49, n.4, p. 689-720.

PALMEIRA, M.; HEREDIA, B. (2010). Política ambígua. Rio de Janeiro: RelumeDumará - NUAP.

ROCHA, M. M.; BARBOSA, C. F. (2008). Regras, incentivos e comportamento: as comissões parlamentares nos países do Cone Sul. Revista de Sociologia Política, v. $16, \mathrm{n}^{\circ}$ suplementar, p. 93-104.

SAMUELS, D. (1997). Determinantes do Voto Partidário em Sistemas Eleitorais Centrados no Candidato: Evidências sobre o Brasil. Dados, v. 40, n. 3.

SOARES, G. A. D.; TERRON, S. (2008). Dois Lulas: a geografia eleitoral da reeleição (explorando conceitos, métodos e técnicas de análise geoespacial). Opinião Pública, v. 14, n. 2. 